\title{
Truncus Arteriosus Type 1: A Case Report
}

\author{
Kowshik Chakma ${ }^{1}$,Nawshin Siraj², Nusrat Ghafoor ${ }^{3}$, S. M. Shaheedul Islam ${ }^{4}$
}

\section{ABSTRACT}

Truncus arteriosus communis (TAC) is a rare heart disorder with the prevalence of approximately $1 \%$, mostly in male newborns with congenital heart defect (CHD). In this disease, aorta and pulmonary artery have not separated during fetal development and both originate jointly from a truncal vessel. In addition, various disorders are reported as associations of mitral and tricuspid valve defects, atrial septal defect (ASD), pulmonary hypertension, increase in heart rate and discharge syndrome.

Key Words: Truncus arteriosus, Ventricular septal defect (VSD), Major Aorto-Pulmonary Collaterals (MAPCA)

\section{INTRODUCTION}

Truncus Arteriosus (TA) is a rare congenital cardiac malformation in which a single common artery arises from the heart by means of a single semilunar truncal valve and supplies the systemic, pulmonary, and coronary circulations. Pulmonary arteries originate from the common arterial trunk distal to the coronary arteries and proximal to the first brachiocephalic branch of the aortic arch. ${ }^{1}$ TA typically overrides a large outlet ventricular septal defect (VSD). We observed a 9 year old boy with TA Type 1 with a major aortopulmonary collateral artery (MAPCA) supplying the right lung. In view of the rarity of this condition it was considered worth reporting.

\section{CASE REPORT}

A 9 year old boy came to our hospital with complaints of shortness of breath and fatigue on exertion for 4-5 years and palpitations for 3 years. He gave a past history of lower respiratory tract infections since infancy. The patient was mildly cyanosed and a continuous murmur in the right parasternal area was formed. Chest radiograph and echocardiography are done.

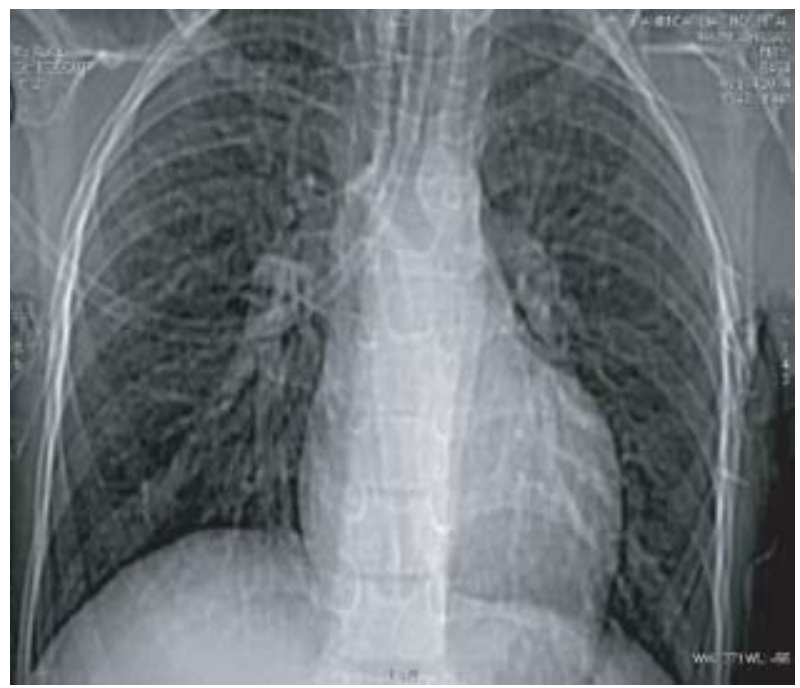

FIGURE 1: A chest radiograph of the patient showed mildly increased cardiothoracic ratio with slightly prominent perihilar vascular markings.

\section{Authors'Information:}

1. Dr. Kowshik Chakma, Associate Consultant, Department of Radiology \& Imaging, Ibrahim Cardiac Hospital \& Research Institute (ICHRI).

2. Dr. Nawshin Siraj, Associate Professor \& Senior Consultant, Head of the Department of Radiology \& Imaging, Ibrahim Cardiac Hospital \& Research Institute (ICHRI).

3. Dr. Nusrat Ghafoor, Associate Consultant, Radiology \& Imaging, Ibrahim Cardiac Hospital \& Research Institute (ICHRI).

4. Dr. S.M. Shaheedul Islam, MBBS, DCH (DU), FCPS (Ped), Fellowship in Pediatric Cardiology, Associate Professor \& Consultant in Pediatric Cardiology, Ibrahim Cardiac Hospital \& Research Institute (ICHRI), Dhaka.

Address of Correspondance: Dr. Kowshik Chakma, Associate Consultant, Department of Radiology \& Imaging, Ibrahim Cardiac Hospital \& Research Institute (ICHRI). Cell: +880 1711129386, E-mail: kowshik1109@yahoo.com 
Echocardiography revealed truncus arising from left ventricle as well as ventricular septal defect on long axis parasternal view. Then CT angiogram was done for better evaluation.

\section{CT Angiogram:}

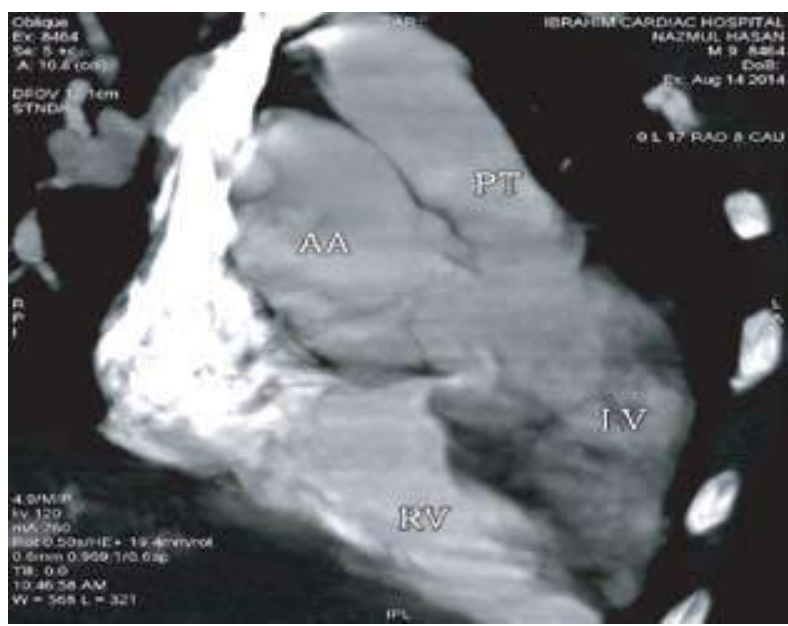

FIGURE 2: Shows high VSD of about $23.2 \mathrm{~mm}$.

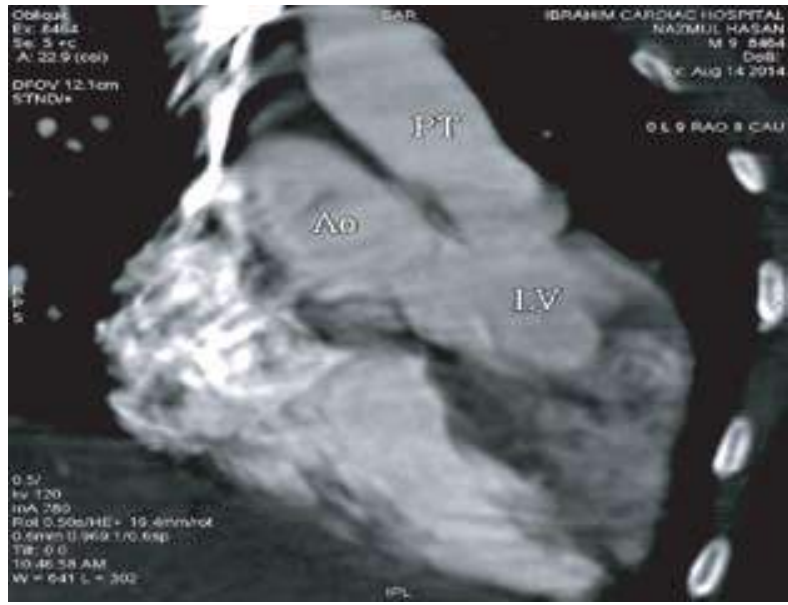

FIGURE 3: One great artery (truncus arteriosus) arising from LV and providing both pulmonary and systemic circulation by single Pulmonary artery and Aorta.

Fig. 2, 3 \& 4 shows Dimensional CT angiographic views in various projections. Above all investigations of the patient revealed that it was diagnosed as truncus arteriosus type I. Then for further treatment he was referred to paediatric cardiac surgery department.

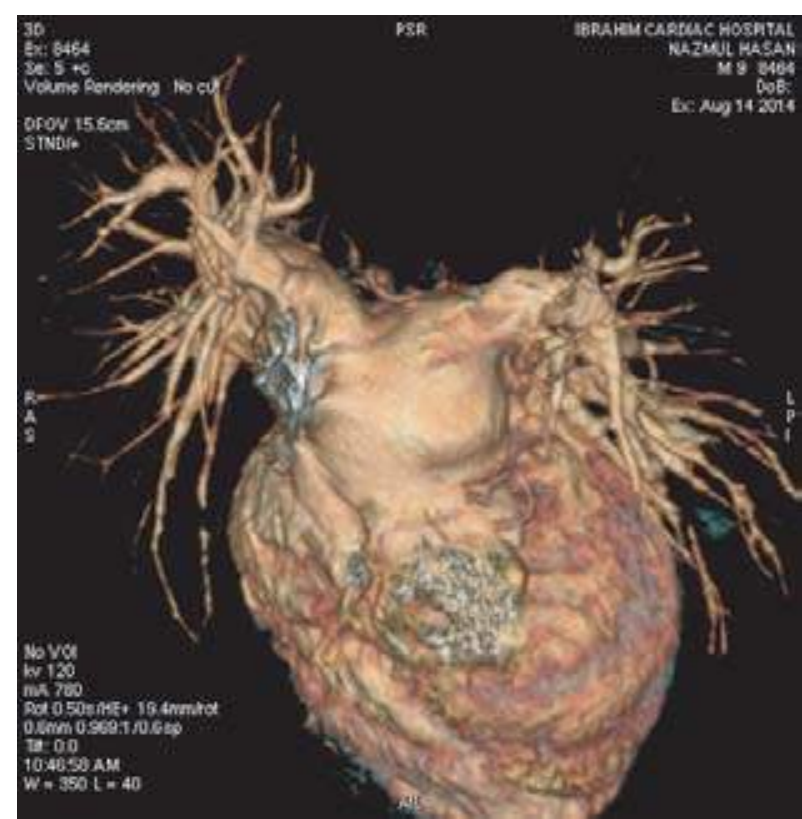

FIGURE 4: The MPA arise from postero-right lateral aspect of great artery and gives rise to RPA and LPA.

\section{DISCUSSION}

Truncus Arteriosus (TA), synonymous with common arterial trunk and Common aorticopulmonary trunk accounts for $0.7-1.4 \%$ of all congenital heart diseases in live-born infants (incidence of $0.03-0.056 / 1000$ live births). ${ }^{1}$ There is no striking sex difference in its incidence although most series reported more males than females. ${ }^{1}$ TA is caused by the failure of the aortico-pulmonary septum to develop and separate the embryonic truncus into the aorta and main pulmonary artery. Etiology is multifactorial and 22q11.2 deletion, maternal diabetes mellitus in pregnancy and teratogens such as retinoic acid and bisdiamine have been blamed. ${ }^{1}$

TA is frequently associated with other cardiac and great vessel anomalies which are present in $34.8 \%$ cases,$~^{2,3}$ such as Right aortic arch (25-30 $\%$ cases) ${ }^{4}$ interrupted aortic arch, aberrant right subclavian artery, abnormal coronary arteries, atrial septal defect, tricuspid atresia, double aortic arch. Occurrence of aortic arch anomalies with TA 
has a strong association with 22q11.2 microdeletion. ${ }^{2}$ Majority of extra cardiac anomalies are associated with $\mathrm{CATCH} 22$ syndrome which is present in $30-35 \%$ patients with TA. ${ }^{1}$ $\mathrm{CATCH} 22$ syndrome (caused by a microdeletion in chromosome 22q11.2 -thought to affect migration or development of cardiac neural crest cells) is a combination of DiGeorge, Velocardiofacial and Conotruncal anomaly, face syndromes manifestations which include cleft lip and palate, thymus and parathyroid dysfunction. Other extra cardiac manifestations reported include unilateral renal agenesis, dysplastic kidneys, holoprosencephaly, esophageal and duodenal atresia, imperforate anus, asplenia. ${ }^{1-3}$

Two classifications have been proposed for TA. Collett and Edward's classified TA into 4 types. ${ }^{2}$ In Type 1, a single pulmonary trunk arises from the TA just distal to the truncal valve. In Type 2 and 3 , the pulmonary trunk is absent and the two pulmonary branches arise from the dorsal wall of the truncus (Type 2) or from the sides of the truncus (Type 3). In Type 4, also called Pseudo truncus, ${ }^{4}$ pulmonary arteries are absent and the pulmonary circulation is supplied by MAPCA arising from the descending aorta. Type 4 now corresponds to pulmonary atresia with VSD. ${ }^{2}$

Van Praagh and Van Praagh classified TA into 2 types based on the presence (type $A$ ) or absence (type B) of a VSD with the later type being rare. ${ }^{3}$ The 2 types are sub classified into 4 subtypes. In type $A 1$, the aorticopulmonary septum is partly formed, resulting in a partially separate main pulmonary artery that arises from the common trunk. The aorticopulmonary septum is completely absent in type A2, and both pulmonary arteries arise directly from the common trunk. Type A2 includes types 2 and 3 of Collett and Edward's. In Type A3 one pulmonary artery is absent and that lung is supplied by collateral vessels (e.g. bronchial arteries) or a pulmonary artery from a patent ductus arteriosus (PDA) or MAPCA from the descending aorta. Type A4 is defined not by the pattern of origin of the pulmonary arteries but by the coexistence of hypoplasia, coarctation, atresia, or absence of the aortic arch. ${ }^{1}$ The truncus consists largely of the main pulmonary artery component with a large PDA supplying the descending aorta. ${ }^{3}$ In these cases a well documented association with DiGeorge syndrome is observed. TA type 1 and type 2 are the most common forms. Type 3 is least common. 5

Patients usually present in infancy with signs of congestive cardiac failure, tachypnea, tachycardia, failure to thrive. ${ }^{4}$ Clinically the condition may have to be differentiated in the neonatal period from other congenital heart diseases causing early heart failure with absent or mild cyanosis and neonatal sepsis.

ECG is nonspecific. ${ }^{1}$ Chest radiograph findings depend on the hemodynamic circumstances. ${ }^{4}$ Cardiomegaly with a small or absent main pulmonary segment (does not develop in its usual position) with pulmonary vascular engorgement (pulmonary arteries receive blood at systemic pressures) are the usual features. In cases with an absent pulmonary artery, the pulmonary vascular pattern is diminished on that side. ${ }^{3} \mathrm{~A}$ right aortic arch is common.

On Echocardiography the origin of the pulmonary artery orifices are best observed in parasternal short axis view. ${ }^{6}$ The long axis-parasternal view shows the size of the truncus with the truncal valve and the VSD as well as the degree of overriding. The single truncal valve is usually tricuspid and is quadricuspid in most of the rest, but may have up to six leaflets ${ }^{6}$ and is frequently incompetent and/or stenotic. The posterior truncal wall is seen in fibrous continuity with the anterior mitral leaflet. 6 Color Doppler study will demonstrate the regurgitation or stenosis of the truncal valve.

Cardiac catheterization with angiography is indicated when pulmonary vascular disease is suspected and to define great vessels and coronary artery anatomy. 


\section{CONCLUSION}

Prognosis is poor without treatment. Corrective operation (Closure of VSD, Separation of pulmonary arteries from primitive truncus and right ventricular to pulmonary artery conduit Rastelli's procedure) is indicated before 3 months of age to avoid development of severe pulmonary vascular obstructive disease. CT angiogram is an excellent modality to depict this malformation and can be used both for pre-operative and postoperative evaluation.

\section{REFERENCES}

1. Cifarelli A, Ballerini L. Truncus arteriosus. Pediatr Cardiol $2003 ; 24: 569-73$.

2. Volpe $P$, Paladini D, Marasini M, Buonadonna AL, Russo MG, Caruso G, Marzullo A et al. Common arterial trunk in the fetus: characteristics, associations, and outcome in a multicentre series of 23 cases. Heart 2003;89: 1437-41. doi:10.1136/heart.89.12.1437.

3. Ferdman B, Singh G. Persistant truncus Arteriosus. Current Treatment Options in Cardiovascular Medicine 2003;5:429-38.

4. Braunwald E, Zipes PD, Libby P. Heart Disease. $6^{\text {th }}$ ed. WB Saunders; 2001. p. 1536-37.

5. Sutton D. Text book of radiology and imaging. $7^{\text {th }}$ ed. Churchill Livingstone; 2003. p. 397-98.

6. Feigenbaum H. Echocardiography. $5^{\text {th }}$ ed. Lea \& Febiger; 1994. p. 418-21. 